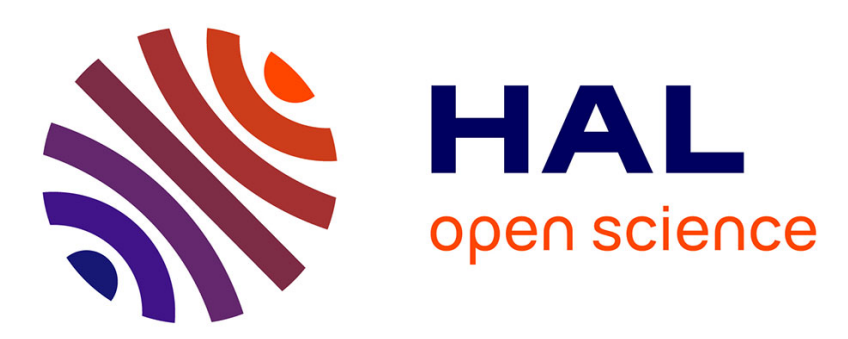

\title{
The impact of chronic low back pain is partly related to loss of social role: A qualitative study
}

Florian Bailly, Violaine Foltz, Sylvie Rozenberg, Bruno Fautrel, Laure Gossec

\section{To cite this version:}

Florian Bailly, Violaine Foltz, Sylvie Rozenberg, Bruno Fautrel, Laure Gossec. The impact of chronic low back pain is partly related to loss of social role: A qualitative study. Joint Bone Spine, 2015, 82 (6), pp.437-441. 10.1016/j.jbspin.2015.02.019 . hal-01219187

\section{HAL Id: hal-01219187 https://hal.sorbonne-universite.fr/hal-01219187}

Submitted on 22 Oct 2015

HAL is a multi-disciplinary open access archive for the deposit and dissemination of scientific research documents, whether they are published or not. The documents may come from teaching and research institutions in France or abroad, or from public or private research centers.
L'archive ouverte pluridisciplinaire HAL, est destinée au dépôt et à la diffusion de documents scientifiques de niveau recherche, publiés ou non, émanant des établissements d'enseignement et de recherche français ou étrangers, des laboratoires publics ou privés. 
Title

The impact of chronic low back pain is partly related to loss of social role: a qualitative study

\section{Authors :}

Florian Bailly ${ }^{1,2}$; Violaine Foltz ${ }^{1,2}$; Sylvie Rozenberg ${ }^{1,2}$; Bruno Fautrel $^{1,2}$; Laure Gossec $^{1,2}$

\section{CORRESPONDING AUTHOR}

Dr. Laure Gossec, Hôpital Pitié-Salpétrière, Service de Rhumatologie, 47-83, boulevard de l'Hôpital - 75013 Paris France

laure.gossec@psl.aphp.fr

Tel: $+\underline{33142178421}$

Fax: +33142177959

Working institution of the corresponding author: Hôpital Pitié-Salpétrière, Service de Rhumatologie, 47-83, boulevard de l'Hôpital - 75013 Paris France

\section{Affiliations}

1 AP-HP, Hôpital Pitié Salpêtrière, Service de Rhumatologie, Paris, F-75013, France ;

2-Sorbonne Universités, UPMC Univ Paris 06, Institut Pierre Louis d'Epidémiologie et de Santé Publique, F-75013, Paris, France 


\section{ABSTRACT}

Objectives: Chronic low back pain (LBP) has an important impact on quality of life, through pain and functional incapacity, but also psycho-social distress. The social participation consequences of LBP have been less explored. The objective was to better understand experiences of patients living with chronic LBP, with a focus on impact on relationships with family, friends and work colleagues.

Methods: Monocentric qualitative study in a tertiary-referral centre in Paris, France. Participants had chronic mechanical LBP. Semi-structured interviews were conducted during 4 focus groups discussions focusing on living with LBP. Verbatim was categorized and coded using thematic content analysis.

Results: Twenty five persons (11 men, 14 women) participated; ages ranged 25-81 years. Participants often reported a negative self-perception in social interactions, with shame and frustration regarding their difficulties to perform activities of daily living. They often felt misunderstood and unsupported, partly due to the absence of visible signs of the condition. Participants suffered from the negative collective image attached to LBP ("benign/psychological disease"). LBP resulted in some patients in a significant loss of social identity with perceived impossibility to perform one's social role at home and at work. In contrast, family and friends were sometimes a support and helped in pain management.

Conclusion: A systematic assessment of social role is needed in LBP care.

Key Indexing Terms: Low Back Pain; Qualitative Research; Social Interaction 


\section{Introduction}

Chronic low back pain (LBP) is a common condition which has an important impact on quality of life [1], resulting in important costs to society. As defined by the World Health Organisation, this condition is accepted as a biopsychosocial phenomenon in which anatomical injury interplays with other factors [2].

Beyond pain and disability, psychological and social aspects have a significant impact on living with chronic LBP [3-12]. Mental aspects of chronic LBP are related to psychological distress, in particular anxiety and depression [3-7]. Patients develop different active or passive, positive or negative, coping strategies to deal with the pain and functional limitations [8,9,11-13]. Relationships with others may also play an important role in LBP $[4,14]$. Psychosocial factors in both private life (e.g., low emotional support) and in the workplace (low workplace social support, low job satisfaction) are risk factors for chronic back pain [15]. "Lack of a support person to talk to about problems" and "poor relationships with peers or supervisors" are "yellow flags" identifying patients at risk of chronic LBP [16].

The impact of relationships with family and friends on living with chronic LBP was briefly explored only in a few qualitative studies [5,17-21]: Participants reported in one study being a burden to their families with increasing misunderstanding as time went on with no diagnosis or formal explanation [5].The other studies did not explore in depth the role of social participation in LBP [17-21]. On the other hand, relationships with health professionals have been well evaluated: individualized care, clear explanations, reassurance, discussing psychosocial issues and future options enhances positive relationships [22-24]. In fact, it appears that patients with LBP who have greater social participation may have also a better physical health status [25].

Psychosocial and relationship aspects are important not only to better understand LBP but also can be an element to guide its management [2]. The management of LBP needs to take into account the physical aspects of the disease, but also in this context, social interactions, which can be targeted by specific rehabilitation programs. Identifying experiences of patients living with chronic LBP and their perception of 
relationships with others, both in the private sphere or at work, can be useful to develop effective methods of reintegrating chronic LBP patients in the work place [2].

Most of the research on the psycho-social aspects of chronic LBP was performed using instrument-based questionnaires, surveys, or epidemiological data sets. Qualitative research methods involve the systematic collection, organization and interpretation of textual material derived from talk or observation, and are more relevant than quantitative studies for further in-depth understanding of LBP patient experiences [26].

This study aimed to better understand experiences in relation with participation, and social difficulties of patients living with chronic LBP, with a focus on impact on relationships with family, friends and work colleagues. 


\section{Material and Methods}

A qualitative study based on the focus group interview method [27] and with an epistemological outlook was conducted. The results are presented according to the framework of the consolidated criteria for reporting qualitative research (COREQ) [28].

The present study was reviewed and approved by the research ethics board of the Pitié-Salpêtrière Hospital, and patients provided written informed consent.

\subsection{Recruitment and participants}

Outpatients from a public university hospital and two private practices in Paris, France were invited to participate in focus groups interviews if they had sub-acute or chronic nonspecific low back pain, and were fluent in French; but in fact all patients included had chronic LBP. The only exclusion criterion was recent back surgery (less than 3 months). Particular attention was paid to the selection so as to obtain a wide spectrum across demographics (particularly age and educational level). A minimum of five participants in each group was required to ensure response diversity, and a maximum of ten participants to facilitate discussion in the focus group process.

\subsection{Focus groups design}

An interviewer guide was developed to conduct the semi-structured interview, which consisted of general and specific questions, supplemented by probes. Focus group methods are particularly adapted for broad topics like living with LBP. This form of qualitative research was preferred to individual interviews in order to stimulate exchanges, to provide a more comfortable setting for discussion while lessening respondents' anxiety and to stimulate interactions among group participants. The focus groups were moderated by a rheumatologist (LG) and lasted 90 to $120 \mathrm{~min}$; a second physician (FB) took additional notes that contributed to the data analysis. Before beginning the session, demographic characteristics were collected from the participants. The lead interviewer posed questions to the group as a whole, although individual involvement and participant interaction were encouraged. Participants were asked to describe their behaviour, beliefs and mind-sets regarding LBP and its 
impact. First, the general impact of LBP was discussed, then some specific aspects related to social life participation (including family life, friendships and work interactions) were addressed. The general introductory question about relationships was "How do you manage relationships with others with your chronic LBP?" Relations with health professionals and therapeutics of LBP (medications, spine injections, back school...) were not discussed. In the middle of the session, the facilitator summarized the main topics and opinions of the participants, and invited them to develop others aspects or other opinions about LBP.

\subsection{Number of subjects}

The guiding principle in determining sample size in qualitative research is theoretical saturation which is reached when ongoing data collection no longer yields new information and insights. [29]. This was the case in the present study.

\subsection{Data analysis}

The sessions were recorded and subsequently transcribed. The focus group transcriptions were analysed by two researchers (FB and LG). using directed and summative qualitative thematic content analysis methods [30] Five steps were followed: (I) Transcripts were read to gain a contextualized impression of the discussion, and preliminary themes chosen. (II) Units of meaning were identified and coded. (III) Similar codes were condensed in categories. (IV) Descriptions were then summarized to establish concepts. (V) Descriptions and concepts were reviewed by the other co-authors, experts in LBP. Furthermore, one of the patients participating checked the final concepts for face validity. Due to anonymised data analysis, it was not possible to link a comment to a specific participant. The qualitative findings are presented as descriptive summaries and illustrated by quotes from the transcripts. 


\section{Results}

\subsection{Participants}

The sample consisted of 25 participants, 11 men and 14 women (Table 1). Patients participated in one of 4 focus groups with 5 to 9 participants per focus group. age, sex, pain intensity, duration of pain, occupation, duration of work disability, family status They ranged in age from 25 to 81 years, with a median age of 50 years. Disease duration ranged from 1 to 35 years, with a median duration of 10 years. Median visual analog scale for pain was 4 out of 10 (range, $0-8$ ). Eighty percent had radicular pain associated with back pain (in case of presence of radicular pain, the back pain was predominant), 5 participants (20\%) were on sick leave while 16 (64\%) were in the workplace, 2 were retired, 1 was unemployed and 1 was work disabled. Sixteen participants (64\%) had benefited from intensive back rehabilitation [31].

\subsection{Impact of $L B P$}

The predominantly negative impact of LBP on participation is summarized in figure 1 .

\subsubsection{Self-perception in the context of participation}

The majority of the participants voiced a negative perception of themselves, both at work and at home (Figure 1), due to reduced physical capacity but also to other people's perceived reactions:

At work, I feel like a dead weight, my employer prefers having someone else working for him so I feel like I'm bothering everyone, I feel useless.

Because of this negative perception, some participants also felt ashamed:

I'm ashamed of being disabled, I'm ashamed to ask my wife to help me.

\subsubsection{Perception by others in the context of participation}




\section{Feeling misunderstood}

Because of the discordance between physical capacity and a normal physical aspect in LBP, many patients reported feeling misunderstood by others. Participants often reported a negation of their disease, as a non-real pathology or a psychological disease only ("Because it can't be seen, it doesn't exist"). A participant reported that only surgery recipients are perceived as seriously ill.

People have difficulties understanding my disease: for them, if you aren't having surgery, you don't want to get better.

Some participants felt perceived as lazy and/or as a cheat:

I think, in the mind of some people, I'm perceived as a sham. When I say I have back problems, they say "that's not possible, you're too young to have back problems".

\section{Family and friends as support}

For some participants family or friends provided assistance, such as listening and understanding the pain management problems; some played a motivational role by pushing patients to have more activities.

I always try to be in regular contact with people in associations rather than remaining alone. On weekends, I try to do something with my children even if I have back pain. I have to move, I have to go out because life goes on.

Having social activities was also often reported as an effective way to focus their attention on something else and forget the pain. It was seen as a component of the management of LBP.

When you move around, sit at a terrace and have a drink and watch other people, you get to think of other things than your LBP. Going to the theatre, or any other activity gives an opportunity to escape our disease. We can forget the pain, or even if the pain is always there, it doesn't matter. 
Social role was significantly altered at work, with difficulties to maintain constant productivity and high variability in levels of functional disability due to LBP. For example one participant reported that a few days after his return to work, his employer forgot his back problems. The employer performed "minor changes, like an ergonomic chair, to avoid [other measures]" without considering LBP as a chronic disease.

Some days, due to the pain, I just cannot get out of bed though I want to. Getting my employer to understand this appears to be an impossible task. Work is planned, independently of our condition, and we have to do it.

Some participants also felt they could not fill their social role in the workplace and they had to rely on other colleagues.

I feel out of my place, I get the impression l'm giving a lot of work to my colleagues and my work gets unloaded on someone else. I always need help so they have to do more than a full time job to compensate.

\subsubsection{Social role and societal beliefs relative to LBP}

\section{A frequent disease}

Patients reported they felt misunderstood perhaps because of the high prevalence of LBP. It was called the "disease of the century", but, as a frequent condition, it was not perceived as a severe and debilitating illness.

When I say to people around me I suffer from back pain, they answer: " that's nothing, it's only temporary, you'll be fine. Everyone has back pain, you don't have a cancer ».

\section{$\underline{\text { A benign disease }}$}

Comparison with diseases perceived as "severe" by two of the participants were mentioned: one with a breast cancer, one with multiple sclerosis. Both women reported more difficulties to manage their back pain in their relationships with others than for those severe diseases. 


\section{Negative psychological image attached to LBP}

Back pain was perceived as a psychological disease, without physical explanation to the pain. Participants received suggestions to consult a psychologist to manage the pain.

Some people ask me: "do you have pain?" but also "Do you have personal problems? Perhaps it would be good to see a psychiatrist..." as if it weren't real, as if I was making it up, as if the problem was in my head and not in my back.

These results suggest stigmatization related to back pain and to the sick role in LBP.

\subsubsection{Significant loss of social role}

Participants felt they were unable to perform their social role, both at home and at work. Some participants stated that they were not able to carry a child or to care for their children.

As a father of two young children, I cannot take them out for a walk, I cannot carry them.

Some male participants reported a perceived loss of masculinity due to the impossibility to carry heavy items like luggage. One of them also had to refuse to help other people for physical tasks, which made him feel inadequate, especially given his body type (he was tall and muscular looking).

For example, when we go on holidays, my wife has to carry our luggage. Everyone is looking at me, l'm very muscular and people don't understand why l'm not carrying them. In the subway, women ask me to help them carry their strollers and I have to say "Sorry but I can't help you". I'm perceived as impolite and badly behaved.

Loss of masculinity was also briefly reported by two male participants in intimate situations, but this was not explored in the focus groups.

\subsection{Anxiety, depression and coping patterns were confirmed as important in}

\section{LBP}


Almost all of the participants reported anxiety associated with fear of the future, due to the unpredictable progression of the disease, with unexpected relapses. Some of them described also characteristics of depression. Coping with the pain was described as a long process. Changes in coping patterns over the disease duration were also reported by some of the patients. These aspects have been reported in other studies [3-7] and were not explored in depth in the present study. 


\section{Discussion}

This study evidenced that chronic LBP has often an important and negative impact on self-perception; furthermore patients felt misunderstood by others and had difficulties to manage their social interactions both at home and in the workplace, resulting in a perception of a significant loss of social role (figure 1). On the other hand, social relationships can be a support for patients with LBP and this positive social support should be promoted to reduce the impact of LBP.

This study has some limitations. This was a monocentric study including 25 patients; but recruitment in a tertiary centre and in a private practice and particular attention to obtain a wide spectrum across demographics led to diversity in participants' characteristics. Furthermore, the number of participants was not arbitrarily fixed, in fact the focus groups were continued until no new information emerged from them. The number of focus groups and participants were close to published focus group studies [29]. This study was conducted by rheumatologists, while most studies in this field are conducted by psychologists: in a recent review of qualitative studies on LBP [4], only one [18] of the 33 studies [5-10,13,19-23,32] was conducted by physicians. Thus, some aspects of experiences of LBP could have been under-evaluated. However this is also a strength: it allowed a more clinical approach as the rheumatologists' knowledge about LBP may have provided a more target-oriented analysis of the data. Intimate life, including sexual difficulties, was not explored, due to the collective configuration of the interviews. However focus groups are a relevant way to collect qualitative data and some authors suggest they may even lead to richer data than individual interviews [33].

Most of the participants were at work without sick leave and the median pain visual analog scale was in the moderate pain range (4/10). This might mean participants were coping well or had LBP without major disease. It could be secondary to the long disease duration: most of the patients reported they underwent multiple or long duration sick leave but had returned at work at the time of the survey. Furthermore two thirds of the patients had benefited from inpatient or day-hospital specialized care in a tertiary care unit, the purpose of which is to promote a return to the work-force. 
Family and friends were perceived differently by different participants in the focus groups. Some of the participants highlighted the significant benefits of adequate understanding and support, whereas other deplored the perceived lack of support of their family and friends. Beyond active listening and understanding, social support could have a role in motivational and volitional competencies to enhance activities in chronic LBP patients [34]. In different studies of people with chronic pain including children [35], family and peer network shaped the chronic pain experience. To better manage chronic pain in children or teenagers, intensive interdisciplinary program included parents with specific treatment goals for parents, including parental responses to pain and positive interactions regarding pain [35]. The present results suggest perhaps LBP management programs should consider inviting significant others for education sessions.

Different attitudes toward LBP are linked with the frequent negative collective image since LBP is often considered as an only "psychological" disease. Stigmatization of patients with LBP was frequently reported in qualitative studies, and may even concern stigmatization in relation with health care attitudes [3]. The absence of physically visible lesions probably plays a role in this stigmatisation. Furthermore, the age range of LBP (mainly 20-50 years) may lead strangers to infer physical strength and good health, leading to misapprehensions and thus stigmatisation. The role of the media was highlighted as painting an image of people with chronic LBP as fraudulent, seeking secondary gains. Information and education about LBP could be delivered not only to the patients but also to their social support (as mentioned above) and importantly, to the general population. Some educational psychosocial booklets, like the "back book" [36] could be used to decrease the negative collective image of the disease and to increase the social support of patients, to facilitate the reintegration of LBP patients in their personal environment.

Consequences of LBP at work are well known with a risk of prolonged sick leave [37]. A broader understanding of work and professional relationship factors are an essential prerequisite for treating and preventing work disability related to back pain. A recent study [38] pointed out that for most working patients seeking medical care, lessening of pain is not the only outcome or treatment focus to consider. Work participation and restoring function play major roles in recovery and are beneficial to overall health and mental well-being. In the present study the participants in the focus 
groups highlighted the need to take into account the loss of social role, to ensure a smooth work reintegration [4].

The social role is not altered only in LBP disease but also in many chronic diseases, like osteoarthritis, rheumatoid arthritis, diabetes mellitus, spondyloarthritis or stroke [39]. Most of those diseases, being chronic conditions, lead to psychological impact like depression, partly linked with social role loss. Rehabilitation of patients with stroke showed that depression improvement was linked to social role functioning [39]. This link perhaps may be applied to patients with LBP and will be another argument for developing actions in favour of improvement of social role management. However, in the present study depression was not assessed per se.

\section{Conclusion}

In conclusion, this study highlighted the social aspects of chronic LBP; a holistic management of LBP should take into account social interactions and better identify difficulties and areas of improvements required for patients. The social component of the biopsychosocial model is not well represented in current core-sets of outcome measures [40]. Further studies may lead to the development of a questionnaire centred on social aspects: a questionnaire may allow patients and physicians to recognize areas for improvement. The ultimate goal is to improve the outcomes of chronic LBP. 


\section{Funding:}

This study was funded by an unrestricted grant from the French society of rheumatology (Société Française de Rhumatologie)

Conflicts of interest: None

Acknowledgments: We thank the patients who participated in this qualitative study and the patient-partner who reviewed the results. 


\section{References}

[1] Vos T, Flaxman AD, Naghavi M, Al. A. Years lived with disability (YLDs) for 1160 sequelae of 289 diseases and injuries 1990-2010: a systematic analysis for the Global Burden of Disease Study 2010. Lancet. 2012 Dec 15;380(9859):2163-96.

[2] Waddell G, Burton a K. Concepts of rehabilitation for the management of low back pain. Best Pract Res Clin Rheumatol. 2005 Aug;19(4):655-70.

[3] Bunzli S, Watkins R, Smith A et al. Lives on Hold: A Qualitative Synthesis Exploring the Experience of Chronic Low-back Pain. Clin J Pain. 2013 Jan 30;29(10):907-16.

[4] Snelgrove S, Liossi C. Living with chronic low back pain: a metasynthesis of qualitative research. Chronic Illn. 2013 Apr 12;9(4):283-301.

[5] Vroman K, Warner R, Chamberlain K. Now let me tell you in my own words: narratives of acute and chronic low back pain. Disabil Rehabil. 2009 Jan;31(12):976-87.

[6] Snelgrove S, Edwards S, Liossi C. A longitudinal study of patients' experiences of chronic low back pain using interpretative phenomenological analysis: changes and consistencies. Psychol Health. 2013 Jan;28(2):121-38.

[7] Osborn M, Smith JA. Living with a body separate from the self. The experience of the body in chronic benign low back pain: an interpretative phenomenological analysis. Scand J Caring Sci. 2006 Jun;20(2):216-22.

[8] Busch H. Appraisal and coping processes among chronic low back pain patients. Scand J Caring Sci. 2005;19:396-402.

[9] Young AE, Wasiak R, Phillips $L$ et al. Workers' perspectives on low back pain recurrence: "it comes and goes and comes and goes, but it's always there". Pain. 2011;152:204-11.

[10] Raak R, Wahren LK. Health experiences and employment status in subjects with chronic back pain: a long-term perspective. Pain Manag Nurs Off J Am Soc Pain Manag Nurses. 2006;7:64-70.

[11] Keefe FJ, Crisson J, Urban BJ et al. Analyzing chronic low back pain: the relative contribution of pain coping strategies. Pain. 1990 Mar;40(3):293-301.

[12] Cano A. Pain catastrophizing and social support in married individuals with chronic pain: the moderating role of pain duration. Pain. 2004 Aug;110(3):65664.

[13] De Souza LH, Frank AO. Experiences of living with chronic back pain: the physical disabilities. Disabil Rehabil. 2007 Apr 15;29(7):587-96. 
[14] Glenton C. Chronic back pain sufferers--striving for the sick role. Soc Sci Med. 2003 Dec;57(11):2243-52.

[15] Hoogendoorn WE, van Poppel MN, Bongers PM et al. Systematic review of psychosocial factors at work and private life as risk factors for back pain. Spine (Phila Pa 1976). 2000 Aug 15;25(16):2114-25.

[16] Kendall NA, Linton SJ, Main CJ. Guide to Assessing Psychosocial Yellow Flags in Acute Low Back Pain: Risk Factors for Long-Term Disability and Work Loss. Wellington, New Zeal Accid Rehabil Compens Insur Corp New Zeal Nathional Heal Commitee. 1997;

[17] Cook FM, Hassenkamp A-M. Active Rehabilitation for Chronic Low Back Pain. Physiotherapy. 2000 Feb;86(2):61-8.

[18] Tavafian SS, Gregory D, Montazeri A. The experience of low back pain in Iranian women: a focus group study. Health Care Women Int. 2008 Apr;29(4):339-48.

[19] Campbell C, Guy A. "Why can”t they do anything for a simple back problem?' A qualitative examination of expectations for low back pain treatment and outcome. J Health Psychol. 2007 Jul;12(4):641-52.

[20] Corbett M, Foster NE, Ong BN. Living with low back pain-Stories of hope and despair. Soc Sci Med. 2007 Oct;65(8):1584-94.

[21] Smith JA, Osborn M. Pain as an assault on the self: An interpretative phenomenological analysis of the psychological impact of chronic benign low back pain. Psychol Health. Routledge; 2007 Jul;22(5):517-34.

[22] Slade SC, Molloy E, Keating JL. "Listen to me, tell me": a qualitative study of partnership in care for people with non-specific chronic low back pain. Clin Rehabil. 2009 Mar;23(3):270-80.

[23] Cooper K, Smith BH, Hancock E. Patients' perceptions of self-management of chronic low back pain: evidence for enhancing patient education and support. Physiotherapy. 2009;95:43-50.

[24] Laerum E, Indahl A, Skouen JS. What is "the good back-consultation"? A combined qualitative and quantitative study of chronic low back pain patients' interaction with and perceptions of consultations with specialists. J Rehabil Med Off J UEMS Eur Board Phys Rehabil Med. 2006;38:255-62.

[25] Takeyachi Y, Konno S, Otani K et al. Correlation of low back pain with functional status, general health perception, social participation, subjective happiness, and patient satisfaction. Spine (Phila Pa 1976). 2003 Jul 1;28(13):1461-6; discussion 1467.

[26] Malterud K. Qualitative research: standards, challenges, and guidelines. Lancet. 2001 Aug 11;358(9280):483-8. 
[27] Britten N. Qualitative Research Qualitative interviews in medical research. $\mathrm{Br}$ Med J. 1995;311:251-3.

[28] Tong A, Sainsbury P, Craig J. Consolidated criteria for reporting qualitative research (COREQ): a 32-item checklist for interviews and focus groups. Int $\mathrm{J}$ Qual Heal .... 2007;19(6):349-57.

[29] Carlsen B, Glenton C. What about N? A methodological study of sample-size reporting in focus group studies. BMC Med Res Methodol. 2011;11:26.

[30] Crabtree B, Miller W. Doing Qualitative Research. SAGE; 1999.

[31] Poulain C, Kernéis $S$, Rozenberg $S$ et al. Long-term return to work after a functional restoration program for chronic low-back pain patients: a prospective study. Eur Spine J. 2010;19:1153-61.

[32] Benjaminsson O, Biguet G, Arvidsson I et al. Recurrent low back pain: relapse from a patients perspective. J Rehabil Med Off J UEMS Eur Board Phys Rehabil Med. 2007;39:640-5.

[33] Krueger RA, Casey MA. Focus Groups; a practical guide for applied research. 3rd edition. Inc. SP, editor. 2000.

[34] Mathy C, Broonen J-P, Henrotin Y et al. Development and validation of a questionnaire assessing volitional competencies to enhance the performance of physical activities in chronic low back pain patients. BMC Musculoskelet Disord. 2011 Jan;12:111.

[35] Logan DE, Engle LB, Feinstein AB et al. Ecological system influences in the treatment of pediatric chronic pain. Pain Res Manag. 2012;17(6):407-11.

[36] Symonds TL, Burton AK, Tillotson KM et al. Absence resulting from low back trouble can be reduced by psychosocial intervention at the work place. Spine (Phila Pa 1976). 1995;20:2738-45.

[37] Steenstra IA, Verbeek JH, Heymans MW et al. Prognostic factors for duration of sick leave in patients sick listed with acute low back pain: a systematic review of the literature. Occup Environ Med. 2005 Dec;62(12):851-60.

[38] Costa-Black KM, Loisel P, Anema JRet al. Back pain and work. Best Pract Res Clin Rheumatol. 2010 Apr;24(2):227-40.

[39] Schmid AA, Damush T, Tu W, Bakas Tet al. Depression improvement is related to social role functioning after stroke. Arch Phys Med Rehabil. 2012 Jun;93(6):978-82.

[40] Froud R, Patterson S, Eldridge $S$ et al. A systematic review and meta-synthesis of the impact of low back pain on people's lives. BMC Musculoskelet Disord. 2014 Jan;15:50. 
Table 1. Characteristics of participants in focus groups

\begin{tabular}{|l|l|l|l|l|l|}
\hline & $\begin{array}{l}\text { Total } \\
\text { sample, } \\
\mathrm{N}=25\end{array}$ & $\begin{array}{l}\text { Focus } \\
\text { group 1, } \\
\mathrm{N}=7\end{array}$ & $\begin{array}{l}\text { Focus } \\
\text { group 2, } \\
\mathrm{N}=6\end{array}$ & $\begin{array}{l}\text { Focus } \\
\text { group 3, } \\
\mathrm{N}=7\end{array}$ & $\begin{array}{l}\text { Focus } \\
\text { group 4, } \\
\mathrm{N}=5\end{array}$ \\
\hline $\begin{array}{l}\text { Age, years, median } \\
\text { (range) }\end{array}$ & $51(25-81)$ & $\begin{array}{l}49(42- \\
59)\end{array}$ & $\begin{array}{l}54.5(32- \\
81)\end{array}$ & $\begin{array}{l}46(29- \\
56)\end{array}$ & $\begin{array}{l}60(34- \\
66)\end{array}$ \\
\hline Gender, male, N (\%) & $11(44 \%)$ & $3(43 \%)$ & $2(33 \%)$ & $5(71 \%)$ & $1(20 \%)$ \\
\hline $\begin{array}{l}\text { Low back pain } \\
\text { duration, years, } \\
\text { median (range) }\end{array}$ & $10(1-35)$ & $2(1-35)$ & $7(2-20)$ & $15(4-25)$ & $10(2-25)$ \\
\hline $\begin{array}{l}\text { Pain intensity visual } \\
\text { analog scale (0-10), } \\
\text { median (range), }\end{array}$ & $4(0-8)$ & $4(0-7)$ & $4(0-8)$ & $3(0-4)$ & $6(0-7)$ \\
\hline
\end{tabular}

\section{Figures}

Figure 1 (in a separate file): Synthetic view of thematic contents reported during 4 focus groups on the social impact of LBP 


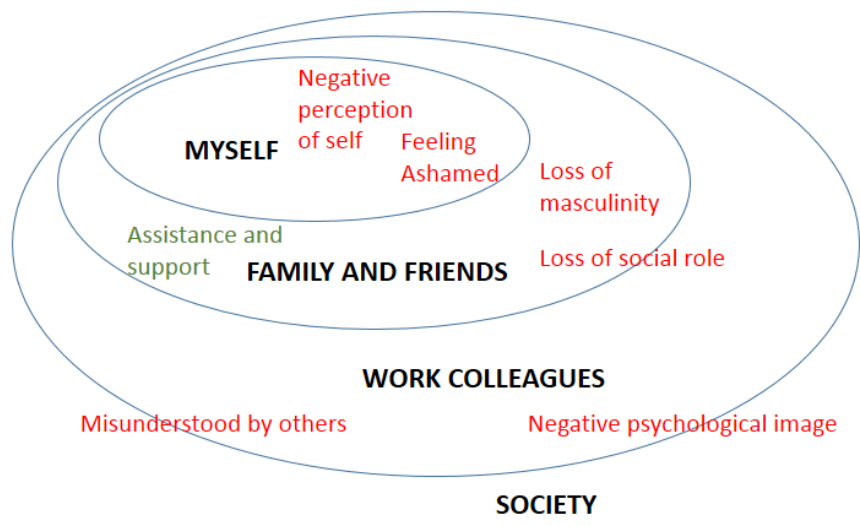




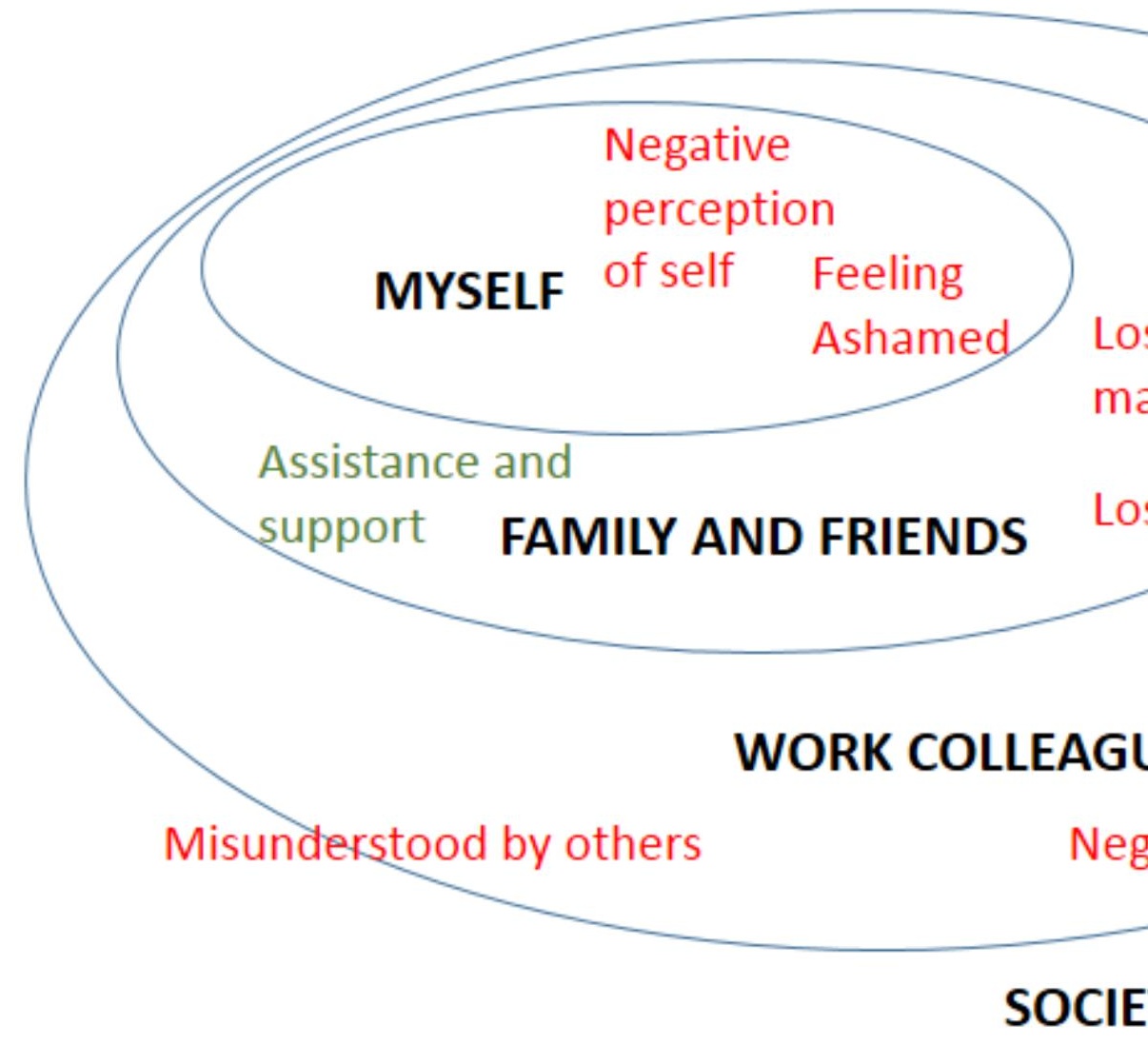

